\title{
A Decision Support System for Planning New Products Introductions in Fresh Produce Supply Chains*
}

Un sistema de apoyo a la toma de decisiones para planificar la introducción de nuevos productos en las cadenas de suministro de alimentos perecederos

Um sistema de apoio à tomada de decisóes para planificar a introdução de novos produtos nas cadeias de suprimentos de alimentos perecíveis

Omar Abumada Valenzuela ${ }^{\mathrm{a}}$

Universidad Autónoma de Occidente, México

omar.ahumada@udo.mx

ORCID: http://orcid.org/0000-0002-0181-3578

Jesus Rene Villalobos

Arizona State University, Estados Unidos

ORCID: http://orcid.org/0000-0003-2530-9760

Juan Carlos Leyva López

Universidad Autónoma de Occidente, México

ORCID: http://orcid.org/0000-0002-4821-6324

Jesús Jaime Solano Noriega

Universidad Autónoma de Occidente, México

ORCID: http://orcid.org/0000-0002-8762-1453
DOI: https://doi.org/10.11144/Javeriana.cao33.adssp

Date received: $26 / 08 / 2019$

Date accepted: $16 / 10 / 2019$

Date published: 20/05/2020

\begin{abstract}
:
This research develops an initial proposal of a Decision Support System -DSS - to plan the production and distribution of new fresh agricultural products. This system is based on a hierarchical approach, which can be applied to enterprises as a planning module or as a stand-alone system for crop production. In this paper is stressed the importance of the DSS for small and mediumsized companies, or for small group of growers that need to improve coordination between their growing and market decisions. The DSS covers the strategic, tactical and operational decisions for every season, focusing on new product introduction. The aim of DSS is increasing the competitiveness of growers in a highly variable and complex marketplace. The agri-food sector still needs evolving to meet increasing demands, understand particular tastes of new consumers and evaluating the requirements of new players.
\end{abstract}

JEL Codes: M15, Q13, Q17

Keywords: Decision Support Systems, new product introduction, agri-food supply chain, production and distribution planning of perishable products.

\section{Resumen:}

Esta investigación desarrolla una propuesta inicial de un Sistema de Apoyo a la toma de decisiones -DSS, siglas en inglés- para la planificación y distribución en la agricultura de nuevos productos perecederos. Este sistema está basado en un enfoque jerárquico, que puede ser implementado en las empresas como un módulo planificado o como un sistema independiente para planificar la producción de la cosecha. En este artículo se resalta la importancia del DSS para las pequeñas y medianas empresas, o para grupos de pequeños cultivadores que necesitan mejorar la coordinación entre sus cultivos y sus decisiones de mercado. El DSS cubre las decisiones estratégicas, tácticas y operacionales para cada estación, centrándose en la introducción de nuevos productos. El objetivo del DSS es incrementar la competitividad de los agricultores en un mercado altamente variable y complejo. El sector agrícola aún necesita evolucionar para satisfacer las demandas crecientes, entender los gustos particulares de los nuevos consumidores y evaluar los requerimientos de los nuevos actores.

Códigos JEL: M15, Q13, Q17

Author notes

${ }^{\text {a } C o r r e s p o n d i n g ~ a u t h o r . ~ E-m a i l: ~ o m a r . a h u m a d a @ u d o . m x ~}$ 
Palabras clave: Sistemas de apoyo a la toma de decisiones, introducción de nuevos productos, cadena de suministro agrícola, producción y distribución planificada de productos perecibles.

Resumo:

Esta pesquisa desenvolve uma proposta inicial de um Sistema de Apoio à tomada de decisões -DSS, siglas em inglês- para a planificação e distribuição na agricultura de novos produtos perecíveis. Este sistema está baseado em um enfoque hierárquico que pode ser levado a outras empresas como um módulo planificado ou como um sistema independente para planificar a produção da colheita. Neste artigo destaca-se a importância do DSS para as pequenas e medianas empresas, ou para grupos pequenos de agricultores que precisam melhorar a coordenação entre seus cultivos e suas decisões de mercado. O DSS cobre as decisões estratégicas, táticas e operacionais para cada estação, se centrando na introdução de novos produtos. O objetivo do DSS é incrementar a competitividade dos agricultores em um mercado altamente variável e complexo. O setor agrícola ainda precisa evoluir para satisfazer as demandas crescentes, entender os gostos particulares dos novos consumidores e avaliar os requerimentos dos novos atores.

Códigos JEL: M15, Q13, Q17

Palavras-chave: Sistemas de apoio à tomada de decisões, introdução de novos produtos, cadeia de fornecimento agrícola, produção e distribuição planificada de produtos perecíveis.

\section{Introduction}

The present research aims to provide fresh produce growers (usually small and medium or cooperatives), with adequate planning tools to tackle new product introduction and the decisions regarding production and distribution of these products, with the objective of maximizing their profitability. The tools we propose on this research are essential for the long-term success of growers in this sector, which are usually operating on an environment that is very complex and competitive, dominated by large processors and retailers.

Growers must improve their competitiveness by developing new products, reducing production costs, logistics costs, product handling, food safety and improving commercialization. Without these requirements, there cannot be value added, for example in the form of better export prices, or reaching high end markets. These same requirements are increasing at national and local markets as well. Since customers demand better access to safe, clean and nutritious foods for a growing and more demanding population, and to improve food safety (Sagarpa, 2010).

If medium and small-scale growers (the vast majority of growers) do not improve on the above mentioned requirements, they will lose competitiveness and could potentially be left out of global markets. Which could have repercussions in the economy of rural areas and could affect food production. This last effect is very negative given that by the year 2050, world population is expected to reach 9,300 million, and the Food and Agriculture Organization of the United Nations expects that food demand to feed these people will increase by $60 \%$ with respect to current food production levels (Alexandratos \& Bruinsma, 2012).

Putting more pressure on current production is the fact that the added population will not only demand more food, but it will require higher levels of healthy food, like fruits, vegetables. For example, in the case of the US there is now an expectation from consumers to have a year round availability of food at the supermarket aisles (traditional and nontraditional foods), which implies more imports and the introduction of new technologies in order to meet this demand (Perosio et al., 2001).

To meet with all these new requirements, current and future food supply chains must keep developing new products and services, which are able to comply and to compete in the global marketplace. There is relevant evidence that the speed of new product development is accelerating, but at the same time the amount of product failures is increasing (Little, Aqueveque, \& Aguilera, 2015).

Nonetheless, the development of new products is becoming an essential part of food supply chains, and one that requires the participation of all the stakeholders, such as seed growers, retailers, farmers, distributors, etc. (Linnemann et al., 2015). It is also true, that for launching successful new products, chains should have 
a focus on consumer preferences, market segmentation, retail channels and the right partners in the supply chain. But as mentioned before, this is not a onetime project, but a continuous process, where companies need to keep learning about consumer trends and their changing needs, in order to continue adapting their products.

This document proposes the development of a hierarchical planning framework for new product introduction in a fresh produce supply chain, to attain efficient and effective fresh produce logistics. Since the fresh produce market is highly dynamic and complex, the present research decomposes the planning process in hierarchical phases: strategic, tactical and operational.

This paper is structured as follows. The first section presents the problem statement. The second one includes a review of pertinent literature. In the third section is about benefits of the proposed research. The following sections describe the planning process for agricultural producers of highly perishable products, which is also an academic contribution in the area of agricultural systems planning in stochastic environments. Finally, the main conclusions are presented, and described research limitations and future research work related to this topic.

\section{Problem statement}

Supply chains of agricultural products are characterized by long supply lead times, combined with significant supply and demand uncertainties (Lowe \& Preckel, 2004). However, these issues are even more complex for the specific case of new product introduction of fresh agri-foods, where producers also face additional marketing uncertainties and a shorter life of the product.

Some of the main factors to consider in the planning of fresh products are the market's prices, demand, and yield. All these factors are for the most part stochastic and present significant interactions among them; one of such interactions is the one formed by the crop's yield, and the price of products. When yields are higher, prices tend to decrease, and the same is true in the opposite direction, when yields decrease, prices tend to increase. All these factors: the prices obtained, the yield and demand, determine the profitability of suppliers in a given period, so growers should consider the individual and combined effect of these variables.

Another source of complexity in agricultural models is the design of the objective function. Producers, who are expected to be the main users of the proposed planning system, have many types of alternatives, frequently with conflicting objectives, when preparing their plans. The grower's objective might involve the maximization of profit and the reduction of risk, or the constant flow of income or he/she may even want the sustainability of his activity through time. Part of this research investigates the different approaches to model the desired objectives of farmers, but most importantly focuses in the real motivations, preferences and behavior of the average grower of fresh produce.

Given the rapid change of consumer demographics and their respective preferences for food, in particular the aging of Western and Asian populations, there is a large risk for food manufacturers and growers alike, that current products would be replaced by new ones that cater to particular trends and special needs for these consumers.

For this reason, there is a constant need to introduce new food products and services catered to the constant changing demands of consumers, not only to preserve their current market positions, but in order to thrive in the coming years. For example in the packaged food segment, the reported figures indicate that over 50\% of current profits are associated with products that have been on the shelf for less than five years (Moskowitz, Saguy \& Straus, 2009). However, these trends have not permeated the fresh food supply chains, since while much relevant material exists for new product development; little has been specifically developed for or applied to the food sector (Grunert et al., 2008). 
Part of this research involves developing a tool for planning new product introduction and their production given limited resources, such as available land, financial resources, and expected market conditions. The proposed work takes the perspective of a farmer who wants to maximize his revenues and avoid the risks of the market. To accomplish this objective, this research proposes the development of a hierarchical framework for supply chain planning of agricultural commodities as part of New Product Development -NPD- effort. At the core of the grower system is an analytical supply chain model that takes the relevant information to render a plan for growing, harvesting and distributing the products in an agricultural cycle.

\section{Literature review}

Traditional agricultural models for supply chains deal with the production, distribution and pricing of commodities such as corn, wheat and soybeans, which have been widely studied in the literature from the perspective of crop selection and resource management (Glen, 1987). However, the complexity of planning and managing of these commodities it is not comparable to that of fresh perishable agricultural products, where most of the times storage of products for later consumption is not an option. To make matters worse, the prices and yields of these products are more variable than traditional commodity products (Zuurbier, 1999).

In a review of models applied to agricultural planning, (Lowe \& Preckel, 2004) observe that decision models for agricultural supply chains were designed to deal independently with the different processes involved in delivering the products to their customers. Other agricultural models are aimed at planning harvesting decisions, machinery selection, farmland use, daily harvest operations and yield and price uncertainty (Glen, 1987). However, these models do not consider the potential benefits that growers can obtain by considering the market and production decisions, in the form of higher returns and reduced risk.

In another review, it was found that more tactical and operational tools are required in order to handle the uncertainty of prices and yields, together with the perishable nature of fresh products. Such models could increase the robustness of the decisions, improving profitability and the sustainability of grower (Ahumada \& Villalobos, 2009).

Recent literature suggest that, due the fast changing in agricultural markets and the new challenges and opportunities that the vast amount of data that are generating, it is important to develop new decision making tools to manage and plan the supply chain for fresh products specially for the small and medium growers (Allaoui et al., 2018; et al., 2018; Flores et al., 2019; Kamble, Gunasekaran, \& Gawankar, 2020; Villalobos et al., 2019).

This research focuses in new product introduction and claims that the benefits could be obtained from coordinating strategic, tactical and operational decisions to improve the successful introduction of new products. The importance of this coordination has been proved empirically by the emergence of growershippers, which are fresh fruit, and vegetable firms that grow, pack, and ship produce to big customers (Kaufman, 2000). These producers bypass traditional wholesalers and sell directly to main retailers, food service companies and ship to other direct markets.

With regards to models that model new product introduction for fresh agricultural products, we did not find any contribution from the literature. The only applications we could find were related to planning the production and distribution of products with perishable or restricted shelf life.

One application develops an approach that integrates short-term production and distribution planning. Further, an aggregation scheme is developed as the interface between the production scheduling and distribution problem. The production scheduling problem is solved through a mixed integer linear program -MILP- modeling approach which is based on a block planning formulation. They develop mathematical 
models and a heuristic solution method to investigate the effect of integrating production scheduling and distribution decisions on the total costs and the quality of the delivered products. The Results of the numerical investigation indicate that the integrated approach significantly improves food quality without considerably increasing production and distribution costs (Farahani, Grunow, \& Günther, 2012).

A similar application aims to investigate the integrated production/distribution and inventory planning for perishable products with fixed lifetime in the constant condition of storage throughout a two-echelon supply chain by integrating producers and distributors. Through the development of an inventory system they integrated production/distribution planning in which for each distribution center, net inventory, shortage, FIFO system and spoilage of items are calculated. This investigation aims to minimize setup costs between products, holding costs, shortage costs, spoilage costs, transportation costs and production costs (Rezaeian, Haghayegh, \& Mahdavi, 2016).

We also include an application that addresses the optimization of the tactical planning for the Fast-Moving Consumer Goods industry using an MILP model, which proposes computationally efficient, methods that accurately consider the shelf-life limitations. The costs when the shelf-life if not considered are $32.12 \%$ higher than the cost when the shelf-life is considered directly.

Other applications that are directly related to the problem at hand, include a tactical plan for fresh produce that include production, distribution and labor decisions with a restricted shelf life and linear decay (Ahumada \& Villalobos, 2011). This MILP application handles most of the decision variables considered in our project, but with the assumption of deterministic demand and production. An improvement, of this paper included a stochastic programming application that considers most of the same decisions, but also considers risk and the probability of negative returns as part of the objective function (Ahumada, Villalobos, \& Mason, 2012).

\section{Benefits of the proposed research}

The first benefit of the proposed research is the development of an integrated framework for the application of planning tools for new product introduction as part of NPD activities, aimed at the needs of grower/ shippers in the supply chain of fresh agricultural products. It is expected that by coordinating production and distribution decisions in the strategic, tactical and operational plans, the growers can have a higher increment in their net revenues than if they planned these decisions independently.

The second benefit from this research is the use of realistic models for the planning of fresh agricultural products. Using stochastic models that are more suited for managing the complexity of the different agricultural decisions and the stochastic data used in these applications. With the use of stochastic tools, it is possible to model more relevant features in the grower's strategic and tactical decisions. For example, the decisions maker -DM- can determine better plans that may reduce costs or maximize benefits, but also reduce the farmer's exposure to risk. For the purpose of controlling risk, the stochastic model can be modified to estimate the benefits of purchasing options and contracts in weather, fuel and market prices. The use of the models proposed can also determine the benefits of proposed technological improvements, such as postharvest treatments and new production methods, which can be better estimated with stochastic models, instead of just using the expected values of stochastic parameters.

The third benefit of our proposed methodology is the design of an operational model that provides short term plans for harvesting and distribution decisions. These operational models coordinate with the tactical plans through a hierarchical approach to planning. The benefit for the grower is better decision tools for maximizing revenue through the adequate distribution of the products to the more profitable markets and through the best transportation decisions for each market. 
Finally, this research develops a methodology for applying the models developed to real applications, by researching the decisions required, the information available and adapting the models to the limitations of real systems. The validation of the assumptions for the models is also important, and this research aims to review the benefits of using the proposed models instead of the current planning methods.

From the perspective of growers' decisions making, the availability of an efficient planning tool for small and medium fresh produce farmers is essential for their survival in a very competitive business. If medium size and small growers have access to efficient planning tools, it may put farmers in more leveled playing field. Moreover, the ultimate beneficiary of the proposed research would be the final consumer of fresh produce.

By allowing a more efficient participation of the small and medium farmers in the fresh produce market the price of the final product becomes more stable and accessible to the general population. Finally, given the particular challenges presented by the production and distribution of fresh products, such as the volatility of prices, product perishability and high production costs; the development of new planning tools for their tactical and operational decisions is a relevant endeavor both in terms of technical and economic contribution.

\section{Planning process for a shipper/grower}

The main concern of our research is to provide the agricultural producers of highly perishable products, such as fresh fruits and vegetables, with adequate tools to perform their seasonal planning. One of the main motivations for conducting this research is that the fresh agricultural industry has become very competitive and complex, thus making planning tools like the ones proposed in this research a necessity for the long-term success of this industry. In addition, the present research provides significant academic contribution in the area of planning of agricultural systems under stochastic environments.

As a representative example of the type of seasonal planning problems addressed on this research, it could be mentioned the planning environment for a tomato crop destined to the fresh market. In tomato production, growers have several planning phases required for growing their crops. There is a pre-season where growers need to make the initial decisions related with production technology, crop planning and land requirements. The second phase is the growing season, which expands from planting the seed all the way to the maturity of the plant. The third phase is the harvesting season, where the producer makes production and packing decisions and finally there is a postharvest phase, which includes all marketing, storage, distribution, and transportation decisions.

Commonly, in the pre-season (Figure 1) growers have two main production alternatives: open field and greenhouse production. Greenhouse production has the advantage of higher quality and more certainty in the amount of production obtained per week but requires a high level of capital investment and operational cost. On the other hand, open field production requires less investment and less operational costs but is prone to be more affected by weather variations. A farmer having the possibility of using open field and greenhouse needs to decide what method and how much land of a product to plant. These decisions are made in part by using information about price and yield estimates. 


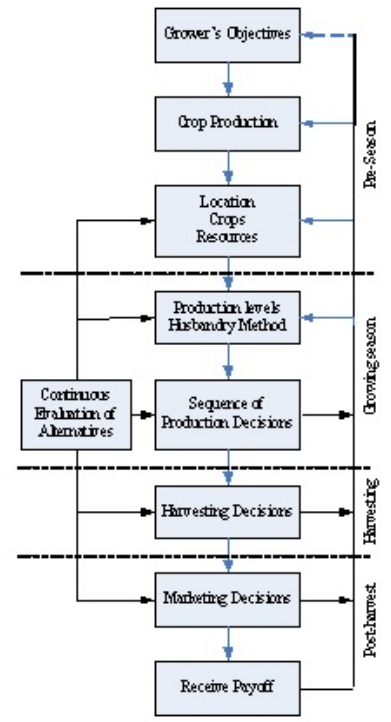

FIGURE 1

Agricultural planning Source: Rae (1977).

Another factor that needs to be considered is when to plant the product to harvest at a targeted time. This decision is important because it may determine the price at which the crop will be sold when harvested. For instance, Table 1 presents different planting dates from August to February with their expected harvesting dates from November to June. This table presents historical information that provides not only the total expected production for each planting cycle, but also the percentage of the total production expected for each week of harvest. With this information it is possible to estimate the amount of each crop to plant and their planting dates in order to cover the market's demand for the season. Then, the farmer needs to consider the best production technology given the particular needs of his customers, his geographical location, his technological capacity and financial resources.

TABLE 1

Production estimates of different crop cycles

\begin{tabular}{|c|c|c|c|c|c|c|c|c|c|}
\hline & & \multicolumn{6}{|c|}{ Harvest by Week (in percentage of total production) } \\
\hline & & \multicolumn{5}{|c|}{ December } & \multicolumn{5}{|c|}{ January } \\
\hline $\begin{array}{c}\text { Date of } \\
\text { Planting }\end{array}$ & Production & 1 & 2 & 3 & 4 & 1 & 2 & 3 & 4 \\
\hline 15-Aug & 1,662 & 10 & 10 & 10 & 10 & 9 & 9 & 8 & 8 \\
\hline 30-Aug & 1,828 & 5 & 5 & 10 & 10 & 10 & 10 & 9 & 9 \\
\hline 14-Sep & 2,373 & 5 & 5 & 6 & 10 & 10 & 10 & 10 & 10 \\
\hline
\end{tabular}

Source: own elaboration.

As it is the case with the production system selection, some planting and growing decisions are also taken at the pre-season phase (before the season starts). Some of the planting decisions involve the selection of the best tomato variety, the selection of the total area to plant of each variety and the planting period. All these decisions are, for the most part, made based on forecasts of the demand and prices expected to be effective in the season ahead. Unfortunately, prices and demand for fresh vegetables are not fixed and have shown historically a high level of variability. For instance, Figure 2 presents the monthly statistics for tomato prices taken over a period of 25 years. The information reported in table shows the maximum, minimum and the 75th and 25th percentiles of the prices, which shows the variability of the market prices. Thus, the initial planning of the production season is marked by uncertainty, complicating the farmer's planning problem. 


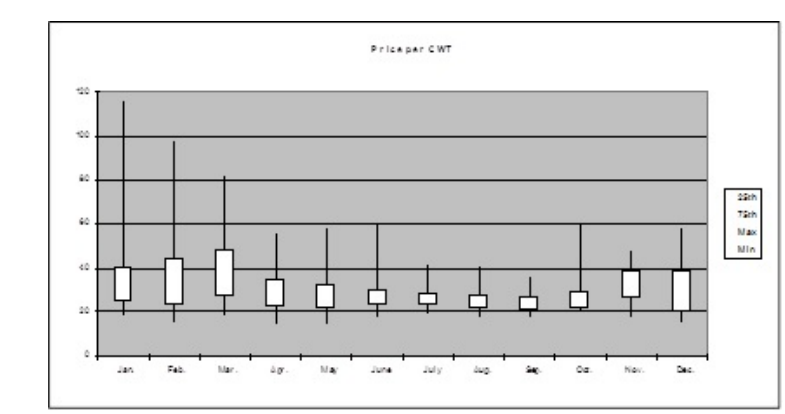

FIGURE 2

Variability of tomato prices for the years 1979-2003

Source: own elaboration.

Afterwards, during the growing season, when the initial planning has already taken place, the farmer needs to prepare the land and perform all the operations required to plant the crops. Later when the farmer has already planted the targeted crops, there are other activities that need to be scheduled as demanded by the crops, such as fertilization and irrigation. This level of planning needs to consider labor, equipment and other resources available to perform all these operations. One feature of these decisions is that they are made once the season advances and the weather conditions and the crop development materializes. For instance, during the growing season, the farmer can rely on better weather forecasts and the feedback obtained from the crop itself to estimate the expected yields from the crop. During the growing season the producer can also obtain better information about the prevailing market prices. In this progression, previous to the harvesting season, the farmer will prepare a desired harvest schedule, and estimate the amount of transportation equipment required to deliver the crops to the selected markets. Finally, once the harvesting phase arrives the farmer schedules the amount to harvest per day of each crop. Then the farmer decides, after getting market information, when and what to ship (sell) to each customer. Decisions in the harvesting phase are influenced by a variable market (prices change almost every week) and a perishable product, so the farmer has a limited amount of time to determine selling and shipping decisions.

This description of the planning environment has used the case of tomatoes to illustrate the overall decision-making process; however, the models developed for this type of problem can be easily extended to other crops, since they have similar planning processes. The aim in this research is to design a general tool that can be used as a starting point for a more detailed planning application that can be adapted to the needs of different growers. The next section starts with the general definition of such a tool and the requirements that it must meet to satisfy the needs of producers.

\section{Envisioned planning environment for NPD}

The previous section has shown that fresh produce growers operate in a complex environment, which includes an uncertain market, variable crop yields, products having short shelf life and long production cycles, making the planning of fresh agricultural products a difficult and risky endeavor. However some producers have managed not only to survive under this environment but also grow to a considerable size, which has allowed them to package, distribute and deliver their products directly to the final customer (Kader, 2002). Nonetheless, new market conditions such as the consolidation of supermarket chains and new purchasing policies by these chains makes the use of advanced planning tools a necessity for these farmers to be an effective market player in this new environment. For instance, it is expected that the consolidation of supermarket chains will continue and increase in the coming years, thus increasing their power. Among the increasing requirements of retailers is the demand for year-round supply of fresh produce and closer relation with their suppliers. The growers that access the final market directly, called grower-shippers, can particularly 
benefit from the planning tools to be developed since they require an adequate design and coordination of their supply chain to meet in the best possible way the market demand. This design needs to include decisions such as choosing the right locations and time for planting, processing and distributing their products.

Grower/shippers form an increasingly important component of the supply chain of fresh horticultural products. The grower/shipper term applies to those individuals or companies, who produce, commercialize and sometimes distribute their own products. These growers require new ways to design and develop their new products, going directly to the consumer and ask their requirements and preferences.

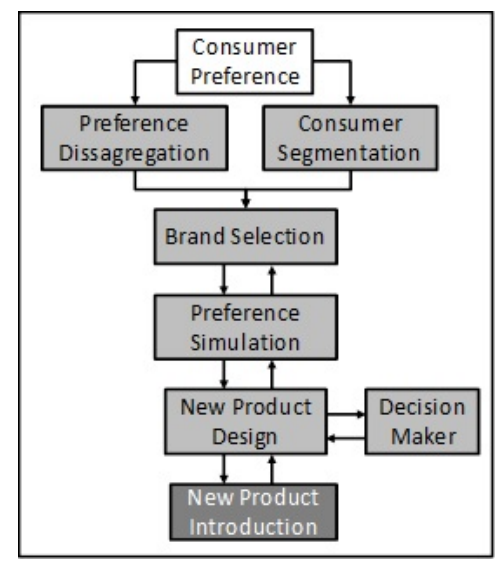

FIGURE 3

Envisioned' planning environment for NPD

Source: own elaboration.

The envisioned planning framework for NPD include as a first step obtaining direct consumer preferences for products, by performing surveys, interviews or obtaining databases from consumers (Figure 3). The second step involves the segmentation and preference disaggregation of consumers. In the segmentation part, we cluster consumers according with their demographic and preference criteria. In the preference disaggregation part, we determine those factors that are more relevant for the consumer, based on their stated preferences, and determine the weight and preference thresholds of those factors, to produce an outranking relation for each consumer based on the relative preferences for the evaluated products.

The third step involves obtaining the outranking relations for each consumer and determine the brand selection model that best fits the consumer choice with their preferences in the outranking relation, to determine their estimated market share. The fourth step involves preference simulation, which initially has to validate the brand selection model by changing some of the initial conditions and test the behavior of the brand selection model. Once validated it can be used to determine the market share of new products or changes to existing products. The output of the simulation is an estimated market share, for products that are not yet on the market or for novel combinations like new products for an existing brand.

The fifth step is new product design; here the DM can input a new product design manually or could use an optimization algorithm that uses the outranking relations, to find those products that provide the best market share within the boundaries selected by the DM. For example, there could be a budget limitation on the kind of product to design, or a technology limitation. Which could have several iterations, until the DM, decides the best product. The iterative nature of the solution process should be present particularly from steps three to the sixth.

Finally step sixth, which we cover on more detail in the present chapter, deals with the production, distribution and other decisions related with product introduction. Given the time-consuming nature of the algorithms and features in this last step, it should only be used with the design of those products that are being seriously considered (it has been revised thoroughly in the previous steps). At the end of these iterations, the 
DM decides which products to launch based on the information of consumers, the estimated demand and production and logistical information, that can better inform him/her of the best course of action.

\section{Hierarchical planning approach for product introduction}

The overall design of the proposed planning environment is based in the development of strategic, tactical and operational plans. The proposed way to handle the decision-making process is to use a hierarchical approach. The reason for taking a hierarchical approach is because the decisions made at the strategic level, determine those at the tactical level, and accordingly, also determine the ones at the operational level. Since by the time the operational decisions are made, the tactical decisions should already have been implemented; then, the solution space for the operational level planning is limited by the tactical decisions.

Similar approaches have been used for the planning of production and distribution in manufacturing operations. In all the applications mentioned, the researchers have found these models to be computationally demanding (Vidal \& Goetschalckx, 2001). The proposed approach is to solve the strategic planning problem first, the tactical planning problem (second), and finally the operational planning problem. Figure 4 shows a schematic of the three-phase approach. Typical inputs for strategic planning include historical price and production yield information, in order to solve what-if questions; the inputs for the tactical problem include the results from strategic planning and the same historical information, while the decision outputs of the tactical plan include how much and when to plant of each potential crop. These two outputs serve as inputs for the operational plan. Typical outputs for the operational plan include irrigation programs, fertilization plans, harvesting and shipment schedules with the respective destination of the shipments.

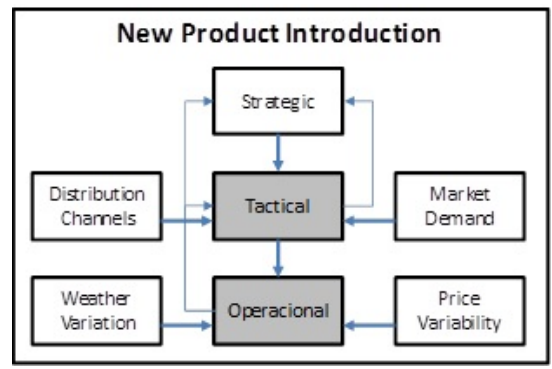

FIGURE 4

Proposed agricultural planning environment

Source: Own elaboration.

The planning environment (shown graphically in Figure 4), include three analytical models, one designed for developing strategic plans, another one for tactical plans and one for operational plans. The tactical model takes the relevant information and renders a plan for growing (when, what and how much to produce) in the tactical phase, taking into account the limitations in terms of resources such as land, investment, expected yield and expected market prices.

An example of the information to be included in the tactical model is the weekly expected demand, the estimated transportation cost and the expected market prices. With detailed information about demand, price and transportation it is possible to determine a tactical plan, which includes the amount of land to plant for each crop, the quantity to harvest and ship every week. Using this information, the tactical model has the necessary information to develop a detailed plan for the planting phase, but with lower resolution for the production and distribution plans, since a more detailed plan (or higher resolution) will be developed with the operational model. As mentioned before, the development of a detailed plan for the operational and tactical decisions at this stage would be impractical given the time gap from planting to harvesting. This gap might make a detailed plan for harvesting and distributing the crops, inaccurate by the time of its 
implementation given the normal changes in the markets. The next section provides the objectives and also the main research contributions from the present research.

\section{Development of the product introduction module}

Once we have established the hierarchical planning process, we now present the general steps that we should follow for the development of a DSS (Figure 5) in a real environment:

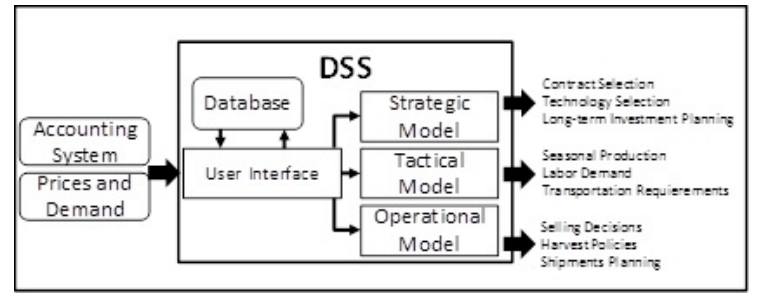

FIGURE 5

Proposed Product Introduction Module and its interactions

Source: Own elaboration.

User Interface and Communications, which queries databases and other relevant systems for tactical and operational planning, such as production costs (labor, seed, chemicals, etc.), management costs, historical yields, customers and other relevant data. Also internal data form the proposed System, such as the potential yields from the different crops, the quality and size obtained from the different seed vendors, and other similar requirements (Burstein \& Holsapple, 2008).

Strategic Model, which handles those decisions that are not necessarily taken each year but affect all the other decisions given their long-term nature. In our case, a clear example is the introduction of new products. But it could include also other decisions like, the adoption of new technologies, supplier selection, and contracting decisions with preferred customers (for one or more years).

Tactical Model, that handles the main decisions in agricultural planning, such as what to plant, when and how much to harvest, and their distribution according to expected demand or the advance purchases from customers (supermarkets and food processors). We propose to include both uncertainty and risk management into this model, given that these issues are very important in the context of agricultural planning and in a very uncertain environment. The assumption of this model is that the DM is a grower-exporter, which is the one that could reap the benefits of better planning tools to match market requirements.

We also expect to evaluate these models and their interaction by developing them and then apply them to a real case study of a grower. One of the objectives is to show the benefits of coordinating productiondistribution decisions. The other objective is to showcase the applicability and ease of use of the proposed methodology, using the information already produced by the growers, but storing it and applying it in a systematic way.

\section{Strategic Model}

The proposed DSS, has the capacity of analyzing the introduction of a new product and analyzing different price and demand scenarios (Figure 6). This feature allows us to develop a model that suggests to the DM the course of action for a strategic decision. For example, advanced risk management decisions, by applying better production methods (less variability in yields) or the design or evaluation of contracting agreements (agreeing on the price of sale and or shipments per week) for one or many production seasons. 


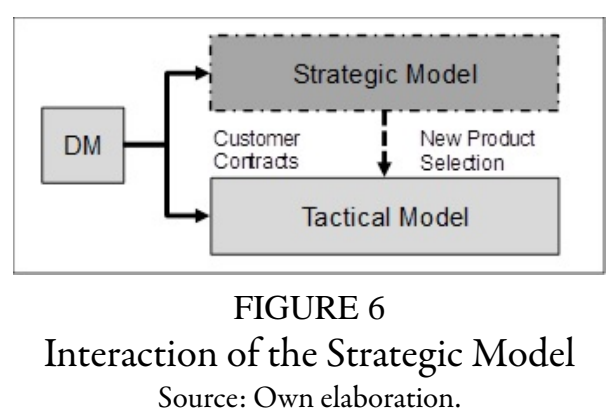

Using this feature, growers can even evaluate the interaction of the proposed risk management improvements before shipping the first loads of a new product and develop better policies that not only improve their bottom line, but also are intended to reduce their exposure to risk. This model should run before the tactical model (should be used in the planning season) or used off-line to keep evaluating these types of alternatives for the coming seasons. Given the nature of what-if questions, this model should have a lot of interaction with the DM, and be flexible enough to allow for different configurations, and for his preferences (for example, his level of aversion to risk), the potential decisions available to him/her, and the particular environment in which he/she operates. For this reason, we plan to work closely with the DM in order to develop a model that fulfills their major needs in strategic planning, but not necessarily all the features demanded, but mainly those with the most benefit in terms of investment.

\section{Tactical Model}

The proposed tactical model is designed to handle the production-distribution decisions of the fresh produce supply chain. This model handles medium term decisions, such as detailed planting plans, and rough estimates of distribution planning, harvesting and growing policies, the decisions and objectives are similar to the ones presented in Ahumada and Villalobos (2011).

In particular, the planting and distribution decisions should support the demand of the products, and obtain a profit given by the selling price. The tactical decisions about new product introduction (planting and marketing), which are made at the start of a growing season, will be inherently risky since the real values of the parameters will be known only with absolute certainty after the crop yield and price have materialized later in the season. For this reason, it is important to consider the possible realizations of all the scenarios, in order to determine the best policy to follow.

The stochastic model incorporates those decisions that highly dependent on the outcome of the stochastic behavior of random variables, such as the selling price and the yield of the products. The proposed model follows the classical two-stage modeling approach in stochastic programming first introduced by Dantzig (2010). Under this approach the stochastic problem is represented in two stages, in which allocations to the first stage (for example how much of a crop to plant) are made to meet a variable but known distribution in the second stage. Between the first and second stage there is some probabilistic event, which is a realization of the stochastic variables. Second stage decisions are all those decisions made after the realization of the stochastic parameters (like price or yields).

An envisioned application of the two-stage approach to our particular problem is shown in Figure 7, as was presented by the authors in a related paper (Ahumada et al., 2012). At the beginning of the planting season, the farmer should decide on how much of each product will be planted without having certain information of weather and market conditions. So the expected outcome of the stochastic tactical plan is the amount to plant of each crop for the coming season. In accordance with the two-stage approach, the information available to the farmer at the time he/she makes his tactical decisions is divided into two sets. The first stage 
set incorporates the planting constraints and the costs associated with the planting decisions. In the second stage the information available is the random distribution of crops prices, the crops' yields, and the demand from the customers.

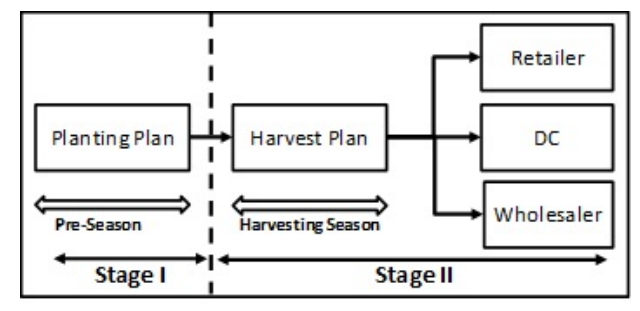

FIGURE 7

Production and distribution decisions in the Stochastic Program Source: Own elaboration.

There are also available the costs and the revenue generated by each one of the decisions in the second stage. Finally, the second stage includes a set of constraints: the demand that must be met from preexisting contracts, the demand that would be optional to meet, such as selling the product in the open market, and the transportation available during the harvesting period. The solution to the problem is then dependent on the first stage decisions (planting), the random realizations (Crop yield, demand and prices) and the second stage decisions (harvesting and distribution).

To model the stochastic behavior, it is assumed that a joint discrete distribution functions of the stochastic parameters can be obtained, which for our particular case are yield $\left(y_{t j t^{2}}\right)$ and market prices $\left(p_{t k i}\right)$ for the planting period $t$, product $k$ customer $i$ and harvesting period $t$, which together form $S$ scenarios. Then it is possible determine the joint probability for each one of the scenarios, which is given by $p r^{s}$.

One problem with the previous formulation is that the traditional objective function is risk neutral, which means that growers are not concerned about their risk exposure due to the variability of the market. From our research in the existing literature, this is not the case, since many growers try to reduce their level of exposure through insurance, subsidies and contracts. This research explores different ways to deal with the risk aversion of the producers. As an example of the potential modifications to the original two-stage model, two potential methods can be provided. The first method is aimed at using recent developments in the formulation of stochastic programming, which include variability reduction terms in the objective function, particularly for second stage costs and revenues (Ahmed, 2006); an example of these terms is presented next, see equation (1).

$$
\begin{aligned}
& \operatorname{Max}: g_{\lambda, h \alpha}[Y]=E[Y]+\lambda h \alpha[Y] \\
& h \alpha[Y]=E\left[(1-\alpha)\left(k_{\alpha}[Y]-Y\right)_{+}+\alpha\left(Y-k_{\alpha}[Y]\right)_{+}\right]
\end{aligned}
$$

Where $\mathrm{k}_{\alpha}$ is $\alpha$ quantile of the distribution of $\mathrm{Y}$, which is the deviation penalty, computed for a desired . percentile (how much to deviate) and $\lambda$ is the weight given to the deviation measure that has to be calculated. This feature works similar to the classical Markowitz portfolio selection model, but with the difference that the present method does not include quadratic terms, making the computation more efficient than Markowitz's method.

The benefit of using stochastic programs is that, unlike the deterministic solutions, which are based in expectations, the stochastic approach can be used to consider alternative scenarios that occur depending on the realizations of the different random variables explicitly considered in the model. Which results in risk reduction, since it narrows the scenarios considered and allows the model to prescribe better plans according to the different scenarios considered in new product introduction. The protection against risk can be in the 
form of better production methods, the use of contracts and through the explicit formulation of the model's objective function. With a realistic tactical model, based in stochastic programming, the growers can evaluate and incorporate several of these decisions and make better policies that not only increase the expected revenue of the farmer, but reduce their risk (one potential result is not launching the product). To select the best approach, several of these formulations are reviewed, and is expected that the one selected provides the best flexibility, tractability and ease of use.

Another important feature in the development of stochastic programs is the composition of the solution space, particularly the second stage (stochastic). For constructing the second stage solution space, it is initially assumed that all of the probability distribution functions are discrete. In the literature there are several examples where the possible outputs of the main factors, like yield and price, are discretized (Rae, 1971). These prices can be discretized into a finite number of states that have a certain probability attached to them. This idea will be further explored to create discrete probability distribution functions. For example, the yield of a crop can be described by probability function with a finite number of states (see Table 2). The states for the yield of the product can also be modeled in the same way.

TABLE 2

Joint probabilities for yield and price for a single crop

\begin{tabular}{|l|c|c|c|}
\hline \multirow{2}{*}{ Yield } & \multicolumn{3}{|c|}{ Market } \\
\cline { 2 - 4 } & Bad & Fair & Good \\
\hline Low & 0.2 & 0.5 & 0.3 \\
\hline Medium & 0.4 & 0.3 & 0.4 \\
\hline High & 0.4 & 0.2 & 0.3 \\
\hline Total & 1.0 & 1.0 & 1.0 \\
\hline
\end{tabular}

Source: Own elaboration.

\section{Application of the new product introduction model}

We now present an application of the DSS for a new product introduction, for a company that exports tomatoes. We assume that a new product has been designed by the other models in the DSS (for example a new line of gourmet tomatoes), with the preference disaggregation, the market segmentation and the brand selection model. The result is a new product design that needs to be evaluated in terms of its production, and logistical feasibility, since the other models already have considered its likeability to consumers, but not the profitability of the product given its particular production and logistical requirements.

We assume this new product is directed to the same supply channels as the other in the company, thus it can share some of the containers, to reduce potential transportation costs. We also assume it uses the same distribution centers and is sold to the same customers. In Table 3, we present the main transportation routes to deliver the products, and the potential transportation modes that could be used to deliver the products to these markets. The routes are from the warehouses of the company (W1 and W2) to the distribution centers of the main customers. 
TABLE 3

Transportation costs for the potential transportation modes and routes

\begin{tabular}{|c|c|l|l|l|}
\hline Warehouse & Cust & Trans Mode & $\begin{array}{c}\text { Time } \\
\text { (Weeks) }\end{array}$ & Cost/Pack \\
\hline W1 & C1 & TRUCK & 0.49 & $\$ 1.73$ \\
\hline W1 & C1 & AIR & 0.14 & $\$ 31.25$ \\
\hline W1 & C1 & RAIL & 0.71 & $\$ 1.25$ \\
\hline W1 & C2 & TRUCK & 0.14 & $\$ 0.50$ \\
\hline W1 & C2 & AIR & 0.14 & $\$ 13.02$ \\
\hline W1 & C2 & RAIL & 0.29 & $\$ 0.40$ \\
\hline W2 & C1 & TRUCK & 0.40 & $\$ 1.39$ \\
\hline W2 & C1 & AIR & 0.14 & $\$ 20.83$ \\
\hline W2 & C1 & RAIL & 0.43 & $\$ 0.81$ \\
\hline W2 & C2 & TRUCK & 0.43 & $\$ 1.24$ \\
\hline W2 & C2 & AIR & 0.14 & $\$ 29.69$ \\
\hline W2 & C2 & RAIL & 0.71 & $\$ 1.18$ \\
\hline
\end{tabular}

Source: Own elaboration.

The model also uses production (labor, seed, fertilizers, packing and others) to determine the cost per box of product and also determines transportation and logistical costs (there might be other costs, such as product loss, due to the time elapsed from harvest to final delivery). Using the model in the DSS, then we can determine the profitability of product in the system. For example, in Table 4 we present the results of the boxes of products shipped to the different customers and the preferred transportation mode. If these products are shipped to these customers, it means it is profitable and feasible to do it according to the volume and price requirements from these customers.

TABLE 4

Shipments to customers in the season

\begin{tabular}{|l|c|r|c|c|c|c|}
\hline & \multicolumn{3}{|c|}{ Truck } & \multicolumn{3}{c|}{ Rail } \\
\hline From & C1 & C2 & C3 & C1 & C2 & C3 \\
\hline Warehouse & 806,989 & 112,198 & & & & \\
\hline DC & & 21,538 & 226,193 & & & \\
\hline Packhouse & $1,045,116$ & & & 7,799 & & \\
\hline Total & $1,852,105$ & 133,736 & 226,193 & 7,799 & & \\
\hline
\end{tabular}

Source: Own elaboration.

Looking at the model and to production and transportation costs, we can conclude that a company that already has a supply chain and some infrastructure in place is better positioned to introduce a new product, that one that has to develop and deliver a product from scratch. Since the established company can share some of the fixed costs of the packinghouse, share transportation costs (combining several products in one shipment) and using the marketing expertise and marketing costs it already uses with the other products. This model can be used to determine better decisions for new and consolidated providers, so they can have a product portfolio that increases their profitability and market share in a very competitive market.

\section{Conclusions}

New product introduction is fundamental for the long-term survival and sustainability of producers. Given the nature of these decisions, growers should thoroughly review the alternatives at hand, and decide objectively with appropriate decision tools. We presented a description of such a tool, and one that has the potential to reap the potential benefits in new market share and profits for growers. Given the complexity 
and importance of these decisions, the validation of the proposed tool requires an iteration of reviews and redesigns of the different research contributions that we propose.

Another objective of the present research, as was mentioned before, is to test the usefulness of our models and their applicability in real settings. To test these features, in the proposed model we will work closely with growers during the development and validation process. Using real data readily available to the producers and updating the models and the DS to better reflect the problem faced by producers.

We expect that another relevant outcome would be the feedback obtained from our interaction with growers. Another one would be the implementation of the system in a real farm, and the validation process. The ultimate test of the usefulness of our system is the demonstration that the model provides a better plan than one given by a producer using the same information and that growers are willing to use it instead of just taking decisions in the traditional way.

\section{References}

Ahmed, S. (2006). Convexity and decomposition of mean-risk stochastic programs. Mathematical Programming, 106(3), 433-446. https://doi.org/10.1007/s10107-005-0638-8

Ahumada, O., \& Villalobos, J. R. (2009). Application of planning models in the agri-food supply chain: A review. European Journal of Operational Research, 196(1), 1-20. https://doi.org/10.1016/j.ejor.2008.02.014

Ahumada, O., \& Villalobos, J. R. (2011). A tactical model for planning the production and distribution of fresh produce. Annals of Operations Research, 190(1), 339-358. https://doi.org/10.1007/s10479-009-0614-4

Ahumada, O., Villalobos, J. R., \& Mason, A. N. (2012). Tactical planning of the production and distribution of fresh agricultural products under uncertainty. Agricultural Systems, 112, 17-26. https://doi.org/10.1016/j.agsy.2012.

Alexandratos, N., \& Bruinsma, J. (2012). World agriculture towards 2030/2050: The 2012 revision. ESA Working Papers 12-03. Food and Agriculture Organization of the United Nations. https://doi.org/10.22004/ag.econ.2 88998

Allaoui, H., Guo, Y., Choudhary, A., \& Bloemhof, J. (2018). Sustainable agro-food supply chain design using twostage hybrid multi-objective decision-making approach. Computers \& Operations Research, 89, 369-384. https: //doi.org/10.1016/J.COR.2016.10.012

Banasik, A., Bloemhof-Ruwaard, J. M., Kanellopoulos, A., Claassen, G. D. H., \& van der Vorst, J. G. A. (2018). Multi-criteria decision making approaches for green supply chains: A review. Flexible Services and Manufacturing Journal, 30(3), 366-396. https://doi.org/10.1007/s10696-016-9263-5

Burstein, F., \& Holsapple, C. W. (2008). Handbook on decision support systems 2: Variations. Springer Science \& Business Media.

Dantzig, G. B. (2010). Linear programming under uncertainty. In Stochastic programming (pp. 1-11). Springer.

Farahani, P., Grunow, M., \& Günther, H.-O. (2012). Integrated production and distribution planning for perishable food products. Flexible Services and Manufacturing Journal, 24(1), 28-51.

Flores, H., Villalobos, J. R., Ahumada, O., Uchanski, M., Meneses, C., \& Sanchez, O. (2019). Use of supply chain planning tools for efficiently placing small farmers into high-value, vegetable markets. Computers and Electronics in Agriculture, 157, 205-217.

Glen, J. J. (1987). Mathematical models in farm planning: A survey. Operations Research, 35(5), 641-666.

Grunert, K. G., Jensen, B. B., Sonne, A.-M., Brunsø, K., Byrne, D. V, Clausen, C. (2008). User-oriented innovation in the food sector: Relevant streams of research and an agenda for future work. Trends in Food Science \& Technology, 19(11), 590-602.

Kader, A. A. (2002). Postharvest technology of horticultural crops (Vol. 3311). University of California Agriculture and Natural Resources. 
Kamble, S. S., Gunasekaran, A., \& Gawankar, S. A. (2020). Achieving sustainable performance in a data-driven agriculture supply chain: A review for research and applications. International Journal of Production Economics, 219, 179-194. https://doi.org/10.1016/J.IJPE.2019.05.022

Kaufman, P. R. (2000). Understanding the dynamics of produce markets consumption and consolidation grow. London: Diane Publishing.

Linnemann, A., Hendrix, E., Apaiah, R., \& van Boekel, T. (2015). Food chain design using multi criteria decision making, an approach to complex design issues. NJAS-Wageningen Journal of Life Sciences, 72-73, 13-21. http:/ /dx.doi.org/10.1016/j.njas.2014.10.002

Little, C., Aqueveque, C., \& Aguilera, J. M. (2015). Producer-consumer misalignment as a possible cause for new food failure: empirical evidence from Chile. Journal of international food \& agribusiness marketing, 27(3), 228-253. $\mathrm{h}$ ttps://doi.org/10.1080/08974438.2014.940120

Lowe, T. \& Preckel, P. (2004). Decision technologies for agribusiness problems: A brief review of selected literature and a call for research. Manufacturing \& Service Operations Management, 6(3), 201-208. https://doi.org/10.1 $287 /$ msom. 1040.0051

Moskowitz, H. R., Saguy, I. S., \& Straus, T. (2009). An integrated approach to new food product development. London: CRC Press.

Perosio, D., McLaughlin, E., Cuellar, S., \& Park, K. (2001). Supply chain management in the produce industry. New York: Cornell University. https://doi.org/10.22004/ag.econ.122645

Rae, A. N. (1971). An empirical application and evaluation of discrete stochastic programming in farm management. American Journal of Agricultural Economics, 53(4), 625-638. https://doi.org/10.2307/1237827

Rae, A. N. (1977). Crop management economics. London: Crosby Lockwood Staples. 525 p.

Rezaeian, J., Haghayegh, S., \& Mahdavi, I. (2016). Designing an integrated production/distribution and inventory planning model of fixed-life perishable products.Journal of Optimization in Industrial Engineering, 9(19), 47-60. https://doi.org/10.22094/JOIE.2016.229

Sagarpa. (2010). Retos y oportunidades del sistema agroalimentario de México en los próximos 20 años. Working Paper, s.n. http://www.sagarpa.gob.mx/agronegocios/Documents/pablo/retosyoportunidades.pdf

Vidal, C. J., \& Goetschalckx, M. (2001). A global supply chain model with transfer pricing and transportation cost allocation. European Journal of Operational Research, 129(1), 134-158. https://doi.org/10.1016/S0377-2217( 99)00431-2

Villalobos, J. R., Soto-Silva, W. E., González-Araya, M. C., \& González-Ramirez, R. G. (2019). Research directions in technology development to support real-time decisions of fresh produce logistics: A review and research agenda. Computers and Electronics in Agriculture, 167, 105092. https://doi.org/10.1016/J.COMPAG.2019.105092

Zuurbier, P. J. (1999). Supply chain management in the fresh produce industry: A mile to go? Journal of Food Distribution Research, 30(856-2016-57418), 20-30. https://doi.org/10.22004/ag.econ.26781

\section{Notes}

* Research paper.

\section{Licencia Creative Commons CC BY 4.0}

Cited as: Ahumada V., O., Villalobos, J. R., Leyva L., J. C., \& Solano N., J. J. (2020). A decision support system for planning new products introductions in fresh produce supply chains. Cuadernos de Administración, 33. https://doi.org/10.11144/Javeriana.cao33.adssp 